\title{
Spin coater based on brushless dc motor of hard disk drivers
}

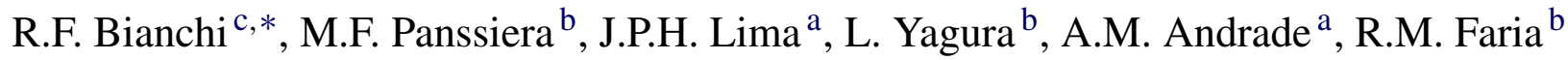 \\ a Departamento de Engenharia de Sistemas Eletrônicos, EP-USP, Av. Prof. Luciano Gualberto, Trav. 3, 158, 05508-970 São Paulo, SP, Brazil \\ ${ }^{\mathrm{b}}$ Instituto de Física de São Carlos, USP, Av. Trabalhador Sancarlense, 400 CP 369, 13560-970 São Carlos, SP, Brazil \\ ${ }^{\mathrm{c}}$ Departamento de Física, UFOP, Campus Morro do Cruzeiro, CEP 35400-000 Ouro Preto, MG, Brazil
}

Received 6 June 2005; received in revised form 15 August 2005; accepted 25 May 2006

\begin{abstract}
We have developed a novel programmable, low cost, spin coater to be used for applications where flat substrates are coated with an uniform thin layer of a desirable material. The equipment is built with dc brushless motor present in most of the hard disk drivers (HDDs). The system offers manual control, wide speed range (from 0 to $10,000 \mathrm{rpm}$ ), spin speed stability and compact size. The paper also describes the use of such equipment for the fabrication of thin poly(o-methoxyaniline) (POMA) films, which are of particular interest for design organic electronic devices, such as diodes, transistor, sensors and displays.
\end{abstract}

(C) 2006 Elsevier B.V. All rights reserved.

Keywords: Spin coater; HDD; Semiconducting polymer; Polyaniline

\section{Introduction}

Spin coating method is a widely used coating method to achieve uniform thin films of materials, often polymers, onto the surface of a substrate by employing the concept of centrifugal force [1-3]. Easy to use, safe and inexpensive, this method is extremely desirable for many applications where high quality layers are required. It is used to produce layers for microcircuit fabrication, compact disks, magnetic disk coatings, polymer electronic devices, etc. [4-7]. Despite the process simplicity, several experimental and theoretical investigations appear in the literature explaining the dependence of the spin coating process on the electrical, optical and morphological characteristics of the films. In such a way that, the control of fluid flow and the fluid evaporation are essential to meet uniform thin films [8], since both contribute to the overall rate of thinning during spinning of a fluid on a disk $[9,10]$. For example, if there is no evaporation of the solvent, the film thickness $(h)$ at long times varies with spin speed $(\Omega)$ and time $(t)$ as $h \propto \Omega^{-1} t^{-1 / 2}$, while in the presence of constant or variable solvent evaporation rates, steady-state film thickness obeys $h \propto \Omega^{-2 / 3}$ or $h \propto \Omega^{-1 / 2}$, respectively [8,9].

In this paper we present the scheme to construct an easy to operate and low cost programmable spin coater based on the brushless dc motor of hard disk drivers (HDDs). Highly effi-

\footnotetext{
* Corresponding author.

E-mail address: bianchi@lme.usp.br (R.F. Bianchi).
}

cient and compact, the control of the motor is achieved by a simple circuitry. The prototype operates with speed controlled for use in the $0-10,000 \mathrm{rpm}$ range. Finally, in order to evaluate the equipment performance, thin polymer films were produced and their thicknesses were compared with results obtained with a commercial spinner equipment.

\section{Spinner design}

The main purpose of this work was to construct a homebuilt spin coater based on the use of a very simple and inexpensive brushless dc motor present in HDDs, which gives us the assurance of a stable and smooth operation [11,12]. Fig. 1 shows one of these motors, which measures about $1 \mathrm{in}$. in diameter.

Control of the dc brushless motor is achieved by a builtin start-up circuit, where the signals from the rotor position is acquired using the back-EMF sensing technique [13]. An electronic system is used to precisely alternate the current in the motor coils, causing the rotor to spin (see Fig. 2). Logic control was written in assembly language and loaded in a PIC 16F877 microcontroller from Microchip Technology Inc. The current is controlled by a drive bipolar circuit in full-wave commutation mode (using push/pull drivers at the output stages) without position sensors [13]. By a proper design, a sample holder vacuum chuck can be added for the rotor, as seen in Fig. 3. The present design permits the control of the output spin speed as function of a knob position (the speed controller), as shown in Fig. 4. 

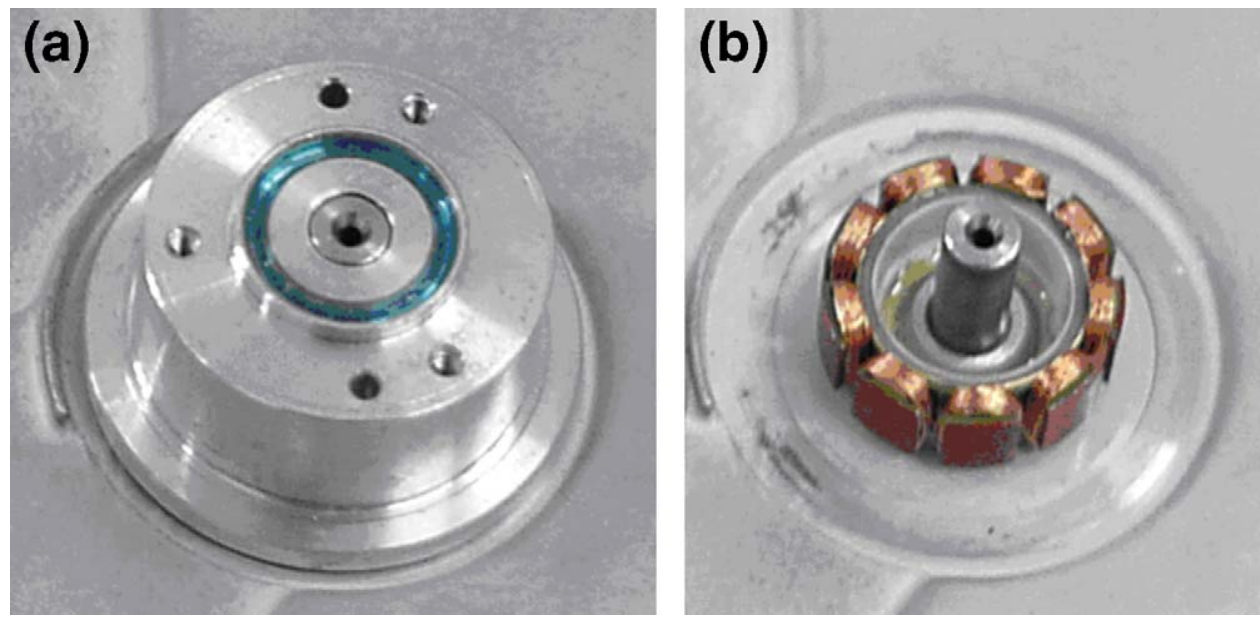

Fig. 1. Photo pictures of the brushless motor obtained from HDDs: (a) rotor and (b) shaft and coils.

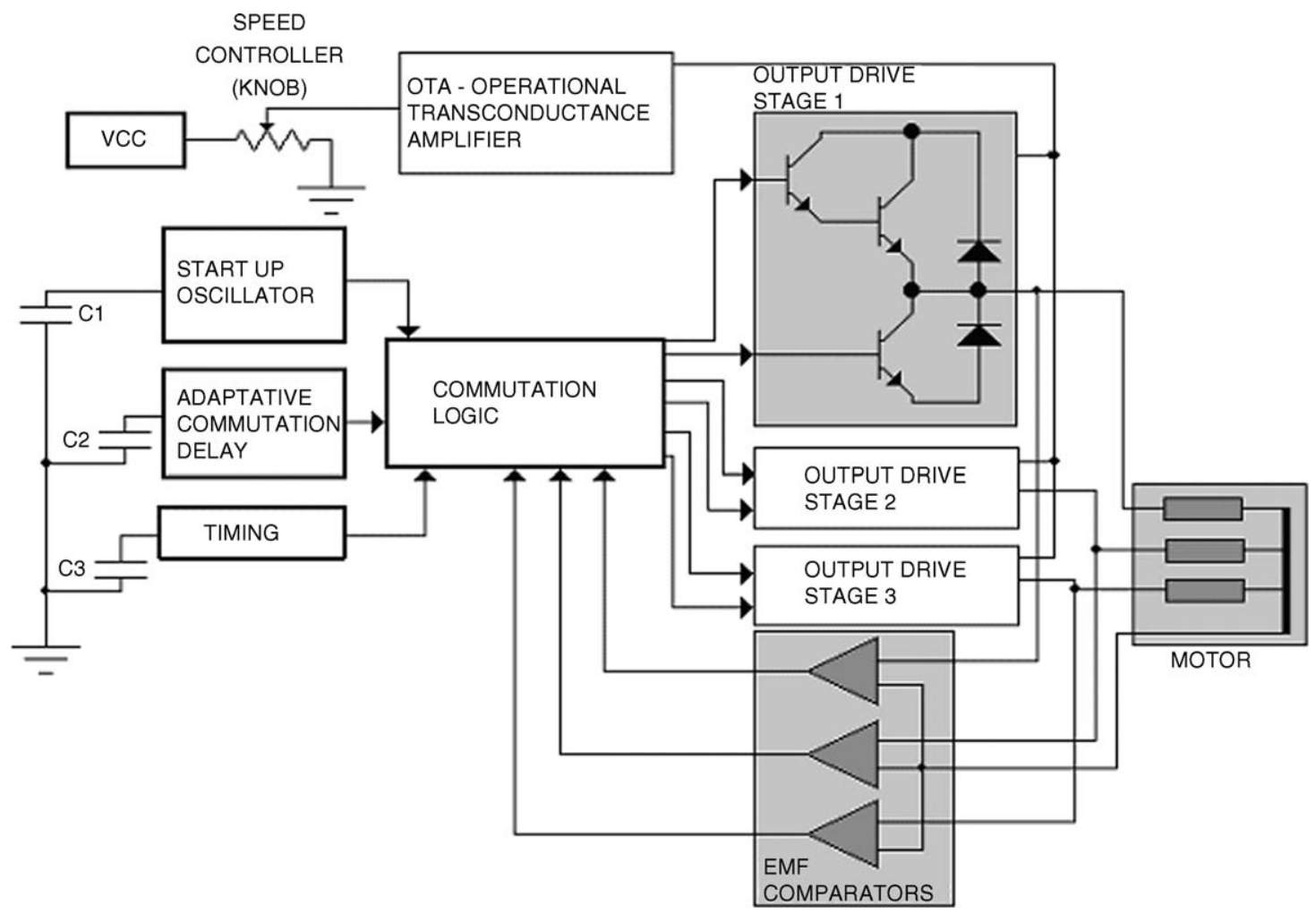

Fig. 2. Schematic illustration of the control circuit.
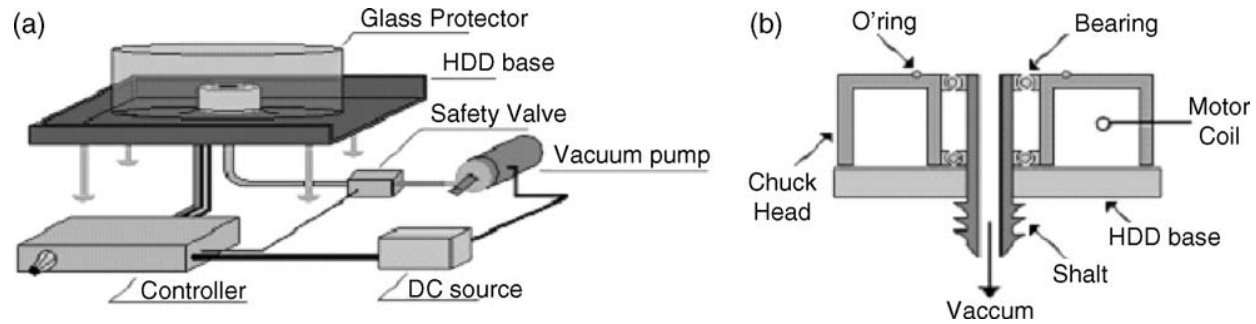

Fig. 3. (a) Schematic representation of homebuilt spin coater and (b) details of rotor. 


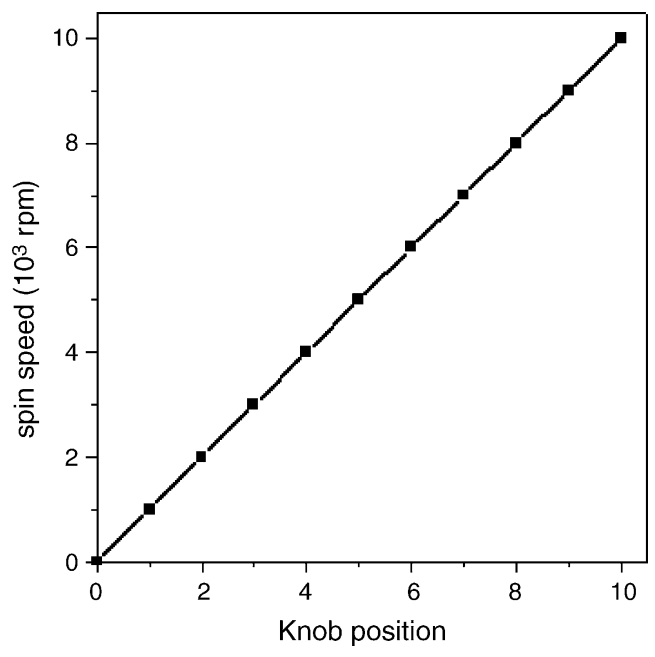

Fig. 4. Control knob position vs. spin speed.

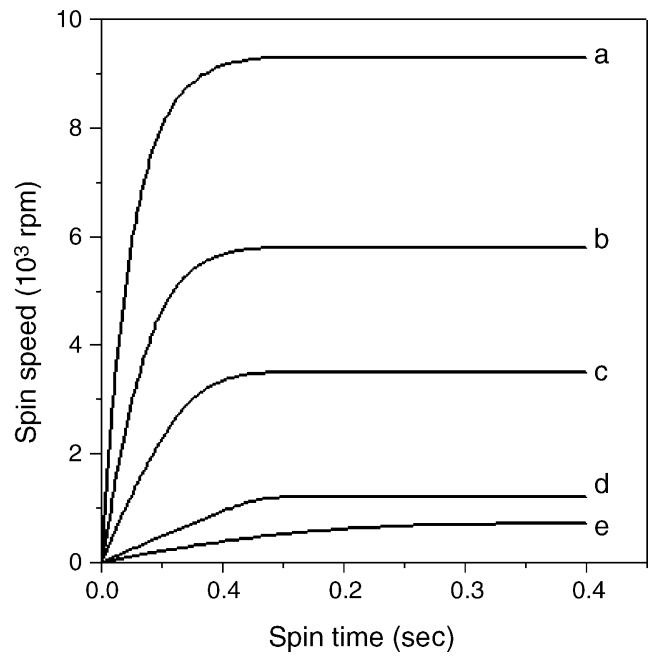

Fig. 5. Spin time vs. spin speed behavior. The letters represent the spin speed setup on the equipment (a, 9300; b, 5900; c, 3500; d, 1200; e, 660 rpm).

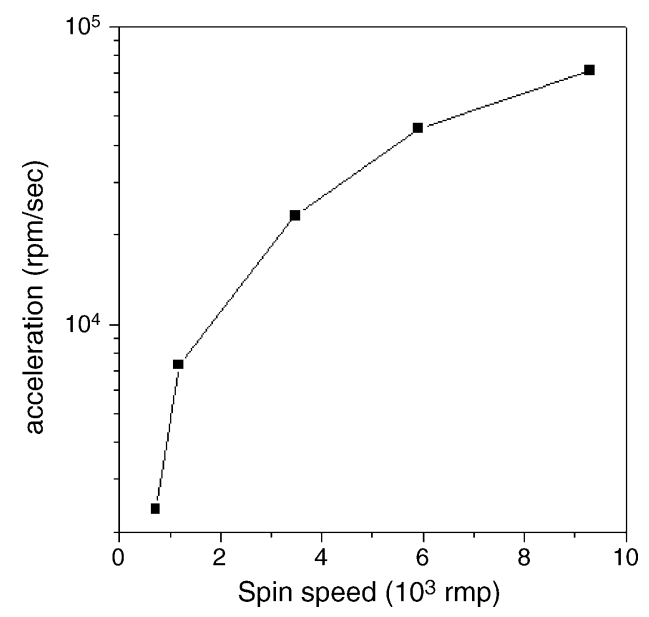

Fig. 6. Spin acceleration vs. spin speed.

\section{Spinner performance}

In order to evaluate the performance of the spinner, Fig. 5 shows a control experiment, which demonstrates the spin speed stability. It presents five curves, each one representing a spin speed setup (a, 9300; b, 5900; c, 3500; d, 1200; e, 660 rpm). The measurements were carried out using scanning head system and a digital oscilloscope.

In Fig. 5 it is observed a time transition between the initial and final speeds, which permits to obtain the spin acceleration, Fig. 6. The spin time and spin acceleration changed, respec-
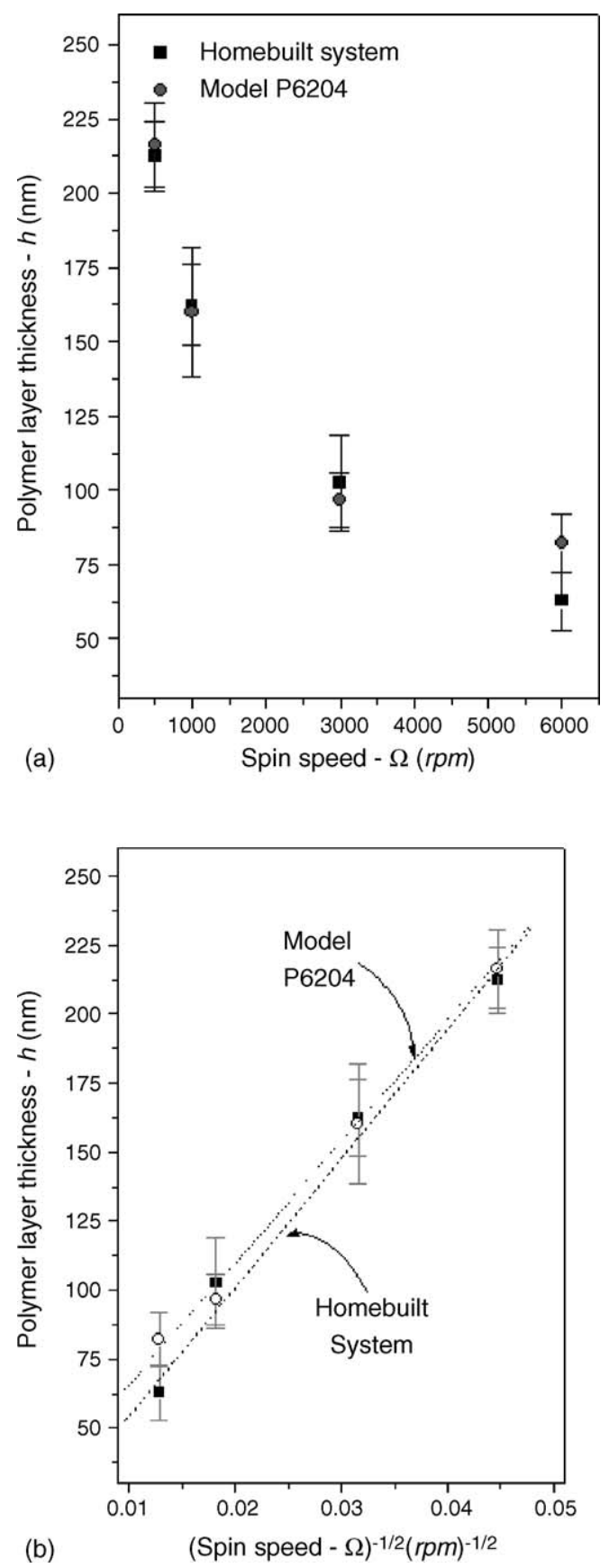

Fig. 7. Effect of spin speed on the thickness of poly (o-methoxyaniline) (POMA) films obtained from (a) homebuilt equipment and (b) from a commercial system (Specialty Coating Systems-Model P6204). 
tively, from $0.3 \mathrm{~s}$ and $2.4 \times 10^{3} \mathrm{rpm} / \mathrm{s}$ (for $660 \mathrm{rpm}$ ) to $0.15 \mathrm{~s}$ and $7.2 \times 10^{4} \mathrm{rpm} / \mathrm{s}$ (for $9300 \mathrm{rpm}$ ), which may be considered as nearly instantaneously for spin coating applications [14].

Finally, during the course of our work programme on the characterization of the spin coater system, the major features to notice were: (1) the stability of the final spin speed for long periods of time, and (2) it was found that the spin speed did not vary when regular or non-regular shaped substrates were fixed on the rotor, i.e. size and mass varying from $1 / 2$ to 2 in. $^{2}$ and from 0.4 to $20 \mathrm{~g}$.

\subsection{Thin polymer film characterizations}

Fig. 7 displays the effect of spin speed $(\Omega)$ on the variation of thickness $(h)$ of thin poly( $o$-methoxyaniline) (POMA) films. Thickness of all samples was obtained using an Alfa Step 500 of Tencor Instruments. The $h$ versus $\Omega$ behavior is showed in Fig. 7(a), while $h$ versus $\Omega^{-1 / 2}$ in Fig. 7(b). The results were obtained from the spinner based on HHD motor (homebuilt system) and also from a commercial system (Specialty Coating Systems, Model P6204), in order to evaluate the performance of the former equipment. POMA is a semiconducting polymer that has received considerable attention in the past decades thanks to its promising applications in a wide variety of electronic devices, including chemical sensors, diodes, and transistors [15]. The polymer was obtained as described elsewhere [16]. POMA films were deposited onto glass substrates using a $15 \mathrm{mg} / \mathrm{ml}$ solution of POMA in chloroform, spin time equal to $30 \mathrm{~s}$ and spin speed varying from 500 to $6000 \mathrm{rpm}$.

It can be seen from Fig. 7(a) that the POMA thin film thickness versus spin speed obtained from both equipment are quite similar: as the spin speed increases from 500 to $6000 \mathrm{rpm}$, it consistently lowers the polymer thickness from around $200 \mathrm{~nm}$ to around $65 \mathrm{~nm}$, respectively. Finally, the experimental data on Fig. 7(b) show that the film thickness obeys a linear dependence on the square root of the spin speed (dash and dot lines), with little scatter on data (standard deviation bars). These results are in agreement with the realistic case of film thickness dependence on the solvent variable evaporation process [9], in agreement with those values observed for other polymer solutions $[8,9]$.

\section{Final remarks}

We have shown in this paper the design and characterization of a simple and low cost spin coater constructed from a brushless dc motor of a HDD, despite the fact that there are commercial spinners with high degree of control and automation. The equipment presents wide speed range, spin speed stability and it is very dependable. In order to improve the performance of the equipment, the control of the acceleration must be further developed. However, even the simple configurations presented in this paper can be used to control the spin speed of regular and non-regular substrates with a great degree of accuracy.

\section{Acknowledgments}

This work was supported by the Fundação de Amparo à Pesquisa do Estado de São Paulo-FAPESP and Instituto do Milênio de Materiais Poliméricos-IMMP/MCT/CNPq.

\section{References}

[1] A.G. Emslie, F.T. Bonner, L.G. Peck, J. Appl. Phys. 29 (1958) 858.

[2] D. Meyerhofer, J. Appl. Phys. 49 (1978) 3993.

[3] M. Sato, I. Fujii, Spin coating process, United States Patent 4,113,492 (1978).

[4] M. Cecchi, H. Smith, D. Braun, Synth. Met. 121 (1-3) (2001) 1715.

[5] D. Chang, D. Yoon, M.D. Ro, I. Hwang, I. Park, D. Shin, Jpn. J. Appl. Phys. Part 142 (2B) (2003) 754.

[6] D.G. Chen, Sol. Energy Mater. Sol. Cells 68 (3-4) (2001) 313.

[7] D.B. Hall, P. Underhill, J.M. Torkelson, Pol. Eng. Sci. 38 (12) (1998) 2039.

[8] P.C. Sukanek, J. Electrochem. Soc. 144 (1997) 11.

[9] W.J. Daughton, F.L. Givens, J. Electrochem. Soc. 129 (1982) 173.

[10] P.C. Sukanek, J. Electrochem. Soc. 138 (6) (1991) 1712.

[11] R. Menon, L.H. Tong, L. Zhijie, Y. Ibrahim, Rel. Eng. Syst. Saf. 75 (3) (2002) 313.

[12] Z.J. Liu, S.X. Chen, Q.D. Zhang, IEEE Trans. Mag. 34 (2) (1998) 483.

[13] An introduction to sensorless brushless dc motor drive application, http://www.st.com homepage, by Microcontroller Division Applications.

[14] D.W. Walters, S.S. Coller, Spin process for highly conformal coatings, United States Patent 5,837,319 (1998).

[15] R.F. Bianchi, R.K. Onmori, R.M. Faria, J. Pol. Sci. B: Pol. Phys. 43 (2005) 74.

[16] D. Gonçalves, D.S. dos Santos, L.H. Mattoso, F.E. Karasz, L. Akcelrod, R.M. Faria, Synth. Met. 90 (1997) 5. 